\title{
STUDY OF GLYCATED HEMOGLOBIN LEVELS IN POLYCYSTIC OVARY SYNDROME
}

\author{
RENUKA P*, SHAKTHIYA T, VINODHINI VM \\ Department of Biochemistry, SRM Medical College Hospital \& Research Centre, Kattankulathur, Kancheepuram - 603 203, Tamil Nadu, \\ India. Email: rpangaluri@gmail.com
}

Received: 22 September 2017, Revised and Accepted: 19 January 2018

\section{ABSTRACT}

Objective: Polycystic ovarian syndrome (PCOS) is often accompanied by insulin resistance, obesity, and cardiometabolic risk factors. Androgen excess-PCOS recommends oral glucose tolerance test or glycated hemoglobin $\left(\mathrm{HbA}_{1 \mathrm{C}}\right)$ to evaluate dysglycemia in PCOS subjects. We undertook this study to evaluate the prevalence of elevated $\mathrm{HbA}_{1 \mathrm{C}}$ levels in PCOS women.

Methods: The study was carried out among 100 PCOS patients from SRM Hospital, 100 healthy individuals were included as controls. Fasting glucose, $\mathrm{HbA}_{1 \mathrm{C}^{\prime}}$ Insulin and Homeostasis Model Assessment-Insulin Resistance Index were estimated.

Results: Patients with polycystic ovary syndrome showed a significant increase in $\mathrm{HbA}_{1 \mathrm{C}}$ levels $(5.799 \pm 1.022 ; 4.96 \pm 0.625$, $\mathrm{p}=0.001)$ when compared to the control group.

Conclusion: We found elevated $\mathrm{HbA}_{1 \mathrm{C}}$ levels in PCOS women categorizing $26 \%$ as prediabetes and $28 \%$ as having type 2 diabetes mellitus.

Keywords: Glycated hemoglobin, Polycystic ovarian syndrome, Pre-diabetes, Type 2 diabetes mellitus.

(C) 2018 The Authors. Published by Innovare Academic Sciences Pvt Ltd. This is an open access article under the CC BY license (http://creativecommons. org/licenses/by/4. 0/) DOI: http://dx.doi.org/10.22159/ajpcr.2018.v11i5.22729

\section{INTRODUCTION}

Polycystic ovarian syndrome (PCOS) is a metabolic disorder with obesityrelated cardiovascular risk factors, infertility, dyslipidemia, and proatherogenic lipid alterations increasing the susceptibility to cardiovascular disease [1]. PCOS subjects are at high risk of developing insulin resistance, dysglycemia and type 2 diabetes mellitus (T2DM). In 2010, a consensus statement by Androgen Excess Society recommended that a $2 \mathrm{~h}$ oral glucose tolerance test (OGTT) should be performed in PCOS women with a body mass index (BMI) $>30 \mathrm{~kg} / \mathrm{m}^{2}$, alternatively in lean women or overweight PCOS women with advanced age ( $>40$ years), a personal history of gestational diabetes mellitus or family history of T2DM [2].

American Diabetes Association (ADA) recommended the usage of glycated hemoglobin $\left(\mathrm{HbA}_{1 \mathrm{c}}\right)$ levels for making a diagnosis of prediabetes and diabetes keeping in view that fasting is not required for estimation of $\mathrm{HbA}_{1 \mathrm{C}}$ and it also gives a time-averaged estimate of blood glucose over the preceding 8-12 weeks [3].

Based on ADA recommendation, $\mathrm{HbA}_{1 \mathrm{C}}$ is endorsed by androgen excess PCOS (AE-PCOS) for assessment of dysglycemia in PCOS women. Hence, the current study was undertaken to determine the prevalence of elevated $\mathrm{HbA}_{1 \mathrm{C}}$ levels in PCOS subjects.

\section{METHODS}

The study protocol was reviewed and approved by the Ethics committee of SRM Medical College Hospital and Research Centre (vide letter No.740/IEC/2015) and informed written consent was obtained from all the participants at the time of enrollment in the study.

The cross-sectional study was carried out among 100 PCOS patients attending infertility Outpatient Department at SRM Medical College Hospital and Research Centre. 100 healthy age-matched women were included as controls. PCOS subjects were selected based on Rotterdam criteria [4]:

Out of the three criteria, two are required for diagnosis:
- Hyperandrogenism

- Clinical (hirsutism or less commonly male pattern alopecia) or

- Biochemical (raised free androgen index or free testosterone).

- Oligo/anovulation.

- Polycystic ovaries on ultrasound.

Subjects were excluded from the study if they had thyroid or other endocrine disorders or taking steroids, insulin-sensitizing drugs.

$4 \mathrm{ml}$ of venous blood was collected from all subjects after $12 \mathrm{~h}$ overnight fasting for plasma glucose and $\mathrm{HbA}_{1 \mathrm{C}}$ in appropriate vacutainers. The samples were processed on the same day. Plasma glucose was analyzed in the Beckman Coulter (California, USA) AU480 chemistry autoanalyzer using kits procured from the same company. $\mathrm{HbA}_{1 \mathrm{C}}$ was measured by high-performance liquid chromatography method using Biorad D-10 (USA) analyzer, and free thyroxine, free triiodothyronine, thyroid-stimulating hormone, insulin, and prolactin were measured using FEIA technique in TOSOH AIA 360 (Japan) hormone analyzer. Homeostasis Model Assessment-Insulin Resistance Index (HOMA-IR) was calculated using the formula:

Fasting insulin $(\mu \mathrm{IU} / \mathrm{ml}) \times$ Fasting glucose $(\mathrm{mg} / \mathrm{dl}) / 405$

BMI was calculated using the formula: Weight $(\mathrm{kg}) / \mathrm{Height}^{2}\left(\mathrm{~m}^{2}\right)$

World Health Organization (WHO) recommendations were utilized to classify patients into underweight if BMI $\leq 18 \mathrm{~kg} / \mathrm{m}^{2}$, normal weight if BMI $18-22.9 \mathrm{~kg} / \mathrm{m}^{2}$, overweight if BMI was $23-24.9 \mathrm{~kg} / \mathrm{m}^{2}$ and obese if $\mathrm{BMI} \geq 25 \mathrm{~kg} / \mathrm{m}^{2}$.

The ADA in 2010 [5] suggested the utility of $\mathrm{HbA}_{1 \mathrm{C}}$ for the diagnosis of prediabetes and diabetes mellitus using the following criteria:

\begin{tabular}{lc}
\hline Normal & $4.3-5.6 \%$ \\
Prediabetes & $5.7-6.4 \%$ \\
Diabetes mellitus & $\geq 6.5 \%$ \\
\hline
\end{tabular}


Statistical analysis

All the data were expressed as the mean and standard deviation. The statistical significance for PCOS and healthy subjects was analyzed using independent Student's $t$-test. Pearson's correlation analysis was done to study the association between $\mathrm{HbA}_{1 \mathrm{C}}$ and BMI in PCOS patients.

\section{RESULTS}

The basic characteristics and mean distribution of biochemical parameters in the cases and controls are depicted in Table 1.

The mean levels of fasting plasma glucose, insulin, HOMA-IR were found to be significantly elevated in the PCOS patients compared to controls.

Patients with polycystic ovary syndrome showed a significant increase in levels of $\mathrm{HbA}_{1 \mathrm{c}}\left(5.799 \pm 1.022 ; 4.96 \pm 0.625,{ }^{*} \mathrm{p}<0.001\right)$ when compared to the control group.

$\mathrm{HbA}_{1 \mathrm{C}}$ levels in PCOS patients were found to correlate positively with BMI, fasting blood sugar $(0.556, \mathrm{p}<0.001)$ and Insulin $(\mathrm{r}=0.221$, $\mathrm{p}=0.027$ ) which are depicted in Table 2 .

\section{DISCUSSION}

In our study, we observed that $54 \%$ of PCOS subjects had elevated $\mathrm{HbA}_{1 \mathrm{C}}$ levels. These statistics are much higher than those reported by a Korean study (31\%) [6]. In a study conducted on Turkish patients with PCOS, only $7.6 \%$ showed $\mathrm{HbA}_{1 \mathrm{C}}$ values more than $5.6 \%$ [7]. About $8.6 \%$ of Danish PCOS subjects had more than $6 \% \mathrm{HbA}_{1 \mathrm{C}}$ [8].

There was a significant difference in mean $\mathrm{HbA}_{1 \mathrm{c}}$ levels between patients with PCOS and controls (5.79 \pm 1.02 vs. $4.96 \pm 0.62)$. This finding is in concurrence with a Korean study which reported mean elevated $\mathrm{HbA}_{1 \mathrm{C}}$ levels $(5.55 \pm 0.34$ and $5.31 \pm 0.24)$ between PCOS patients and controls. In their study, a significant association was demonstrated between PCOS and elevated $\mathrm{HbA}_{1 \mathrm{C}}$ following adjustments for cardiovascular risk factors such as alcohol, BMI, hypertension, smoking, high-sensitivity $\mathrm{C}$-reactive protein, and dyslipidemia, on performing a multivariate regression analysis. They showed that the odds of having increased $\mathrm{HbA}_{1 \mathrm{C}}$ was 6.67 times higher in Korean PCOS patients [6].

We found significantly higher BMI among PCOS patients which correlated positively with the $\mathrm{HbA}_{1 \mathrm{C}}$ levels. Our findings are supported by Legro

Table 1: Mean distribution of biochemical parameters in PCOS cases and controls

\begin{tabular}{llll}
\hline Parameter & Controls & Patients & p value \\
\hline BMI $\left(\mathrm{kg} / \mathrm{m}^{2}\right)$ & $21.486 \pm 1.823$ & $23.207 \pm 4.293$ & $0.0003^{*}$ \\
$\mathrm{HbA} 1 \mathrm{C}(\%)$ & $4.96 \pm 0.625$ & $5.799 \pm 1.022$ & $<0.001^{*}$ \\
FBS $(\mathrm{mg} / \mathrm{dl})$ & $87.91 \pm 11.31$ & $93.51 \pm 16.67$ & $0.006^{*}$ \\
Insulin $(\mu \mathrm{U} / \mathrm{ml})$ & $6.373 \pm 2.144$ & $7.3745 \pm 3.7954$ & $0.022^{*}$ \\
HOMA-IR & $1.376 \pm 0.4879$ & $1.687 \pm 1.0069$ & $0.006^{*}$ \\
\hline
\end{tabular}

Values are expressed in mean \pm standard deviation. The values are statistically significant if the $P<0.05^{*}$. PCOS: Polycystic ovarian syndrome, BMI: Body mass index, $\mathrm{HbA}_{1 \mathrm{c}}$ : Glycated hemoglobin, HOMA-IR: Homeostasis Model Assessment-Insulin Resistance Index, FBS: Fasting blood sugar

Table 2: The Pearson's correlation analysis between $\mathrm{HbA}_{1 \mathrm{C}}(5.799 \pm 1.022)$ and BMI, FBS, insulin, HOMA-IR in PCOS patients

\begin{tabular}{llll}
\hline Parameter & Mean \pm SD & r value & p value \\
\hline BMI $\left(\mathrm{kg} / \mathrm{m}^{2}\right)$ & $23.207 \pm 4.293$ & $\mathrm{r}=0.259$ & $\mathrm{p}=0.0092^{*}$ \\
FBS $(\mathrm{mg} / \mathrm{dl})$ & $93.51 \pm 16.67$ & $\mathrm{r}=0.556$ & $\mathrm{p}=0.0001^{*}$ \\
Insulin $(\mu \mathrm{U} / \mathrm{ml})$ & $7.3745 \pm 3.7954$ & $\mathrm{r}=0.221$ & $\mathrm{p}=0.027^{*}$ \\
HOMA-IR & $1.687 \pm 1.0069$ & $\mathrm{r}=0.343$ & $\mathrm{p}=0.0047^{*}$ \\
\hline
\end{tabular}

The values are statistically significant if the $P$ value is $<0.05^{*}$. PCOS: Polycystic ovarian syndrome, BMI: Body mass index, $\mathrm{HbA}_{1 \mathrm{c}}$ : Glycated hemoglobin,

HOMA-IR: Homeostasis Model Assessment-Insulin Resistance Index, FBS:

Fasting blood sugar, SD: Standard deviation et al. [9] who observed that as BMI increased in PCOS patients, there was an increased prevalence of glucose intolerance. They also showed an independent association between increased risk of T2DM and high baseline levels of fasting plasma glucose, BMI and response to glycemic load. A prospective, randomized study performed in North India on PCOS women showed that Myo-inositol and metformin were effective in decreasing their BMI, thereby improving insulin sensitivity [10].

Fasting glucose levels between $100 \mathrm{mg} / \mathrm{dL}$ and $125 \mathrm{mg} / \mathrm{dL}$ were used for defining prediabetes. Based on this we found that $27 \%$ of PCOS women were having a prediabetic state and $17 \%$ of PCOS subjects came under T2DM ( $\geq 126 \mathrm{mg} / \mathrm{dL}$ ). ADA suggested that $\mathrm{HbA}_{1 \mathrm{C}}$ can be used for assessment of diabetes in PCOS women. The prevalence of prediabetes was $26 \%$, and that of diabetes was $28 \%$ in PCOS subjects using $\mathrm{HbA}_{1 \mathrm{C}}$ for assessment of diabetes in our study. A study on 671 PCOS women from Austria showed a prevalence of $12.8 \%$ and $1.5 \%$ for prediabetes and T2DM, respectively [11]. Some studies have advocated PPBS as a better predictor of overall glycemic status [12].

We categorized PCOS subjects by BMI as non-obese $<25 \mathrm{~kg} / \mathrm{m}^{2}$ ) and obese $\left(\geq 25 \mathrm{~kg} / \mathrm{m}^{2}\right)$ according to the definition for Asians (WHO Western Pacific region, 2000) and the prevalence of elevated $\mathrm{HbA}_{1 \mathrm{C}}$ was analyzed. We found that $45 \%$ of non-obese PCOS subjects had $\mathrm{HbA}_{1 \mathrm{C}} \geq 5.7$ and the number of obese subjects with elevated $\mathrm{HbA}_{1 \mathrm{C}}$ was 10 . The prevalence of pre-diabetes is found to be $35 \%$ among obese and $24 \%$ in non-obese PCOS cases. $50 \%$ of obese PCOS subjects and $23 \%$ of non-obese PCOS cases were diagnosed as T2DM based on the $\mathrm{HbA}_{1 \mathrm{C}}$ levels.

AE-PCOS Society suggested that OGTT must be performed in obese patients or in lean subjects over 40 years of age [13]. In view of our finding, we suggest that even young and non-obese subjects with PCOS need to be screened for type 2 diabetes to ensure early intervention. Comparison of diagnostic methods for identifying pre-diabetes and diabetes in PCOS subjects by Hurd et al. [14] showed that $\mathrm{HbA}_{1 \mathrm{C}}$ was effective in identifying $20 \%$ subjects with normal OGTT as having prediabetes and concluded that PCOS patients should be screened for glycemic status using $\mathrm{HbA}_{1 \mathrm{C}}$ or OGTT.

Elevated $\mathrm{HbA}_{1 \mathrm{C}}$ levels have been associated with risk factors for cardiovascular disease and the presence of metabolic syndrome in many clinical conditions. It has been observed that a $1 \%$ increase in the absolute $\mathrm{HbA}_{1 \mathrm{C}}$ concentration is associated with a 10-20\% increase in cardiovascular risk [15]

In view of the high prevalence of cardiometabolic risk factors and risk of cardiovascular disease, early detection of pre-diabetes is of greatimportance in women with PCOS. A large percentage of PCOS subjects with pre-diabetes were shown to progress to type 2 diabetes in a few years [16]. The rate at which they progressed to develop T2DM was found to be $2-3 \%[17,18]$.

\section{CONCLUSION}

We found elevated $\mathrm{HbA}_{1 \mathrm{c}}$ levels in PCOS women categorizing $26 \%$ as pre-diabetes and $28 \%$ as having T2DM. We suggest that $\mathrm{HbA}_{1 \mathrm{C}}$ may be used as a screening tool for identifying pre-diabetes and T2DM among PCOS subjects due to its advantages such as convenient sampling (since fasting is not mandatory) and less variability due to illness or stress.

Further studies are necessary to assess whether $\mathrm{HbA}_{1 \mathrm{C}}$ is as effective as OGTT as a diagnostic tool for diabetes in patients with PCOS.

\section{ACKNOWLEDGEMENT}

The authors are extremely grateful to Dr. Muthulakshmi, Professor and Head, Department of Obstetrics and Gynecology, SRM Medical College Hospital and Research Center for her constant support in carrying out this study.

\section{CONFLICT OF INTEREST}

All authors hereby declare that there is no conflict of interest. 


\section{AUTHOR'S CONTRIBUTIONS}

All authors have made substantial contribution to the work reported in the manuscript. Renuka. P: Conception and designing of the study, data analysis and interpretation, drafting of the article, critical revision of the article, final approval of the study to be published. Shakthiya. T: Data collection, data analysis and interpretation, drafting of the article Vinodhini VM: Drafting of the article, critical revision of the article, final approval of the study to be published.

\section{REFERENCES}

1. Adams JM, Taylor AE, Crowley WF Jr, Hall JE. Polycystic ovarian morphology with regular ovulatory cycles: Insights into the pathophysiology of polycystic ovarian syndrome. J Clin Endocrinol Metab 2004:89:4343-50.

2. Yildiz BO, Bozdag G, Yapici Z, Esinler I, Yarali H. Prevalence, phenotype and cardio metabolic risk of polycystic ovary syndrome under different diagnostic criteria. Hum Reprod 2012;27:3067-73.

3. Sacks DB, Bruns DE, Goldstein DE, Maclaren NK, McDonald JM, Parrott $\mathrm{M}$, et al. Guidelines and recommendations for laboratory analysis in the diagnosis and management of diabetes mellitus. Clin Chem 2002;48:436-72.

4. The Rotterdam ESHRE/ASRM-Sponsored Consensus Workshop Group Revised 2003. Consensus on Diagnostic Criteria and Long-Term Health Risks Related to Polycystic Ovary Syndrome (PCOS). Hum Reprod 2004;19:41-7.

5. American Diabetes Association. Diagnosis and classification of diabetes mellitus. Diabetes Care 2011;34 Suppl 1:S62-9.

6. Kim JJ, Choi YM, Cho YM, Jung HS, Chae SJ, Hwag KR. Prevalence of elevated glycated hemoglobin in women with polycystic ovary syndrome. Hum Reprod 2012;27:1439-44.

7. Celik C, Abali R, Bastu E, Tasdemir N, Tasdemir UG, Gul A. Assessment of impaired glucose tolerance prevalence with hemoglobin $\mathrm{A}(1) \mathrm{c}$ and oral glucose tolerance test in 252 Turkish women with polycystic ovary syndrome: A prospective, controlled study. Hum Reprod 2013;28:1062- 8.

8. Velling Magnussen L, Mumm H, Andersen M, Glintborg D. Hemoglobin A $1 \mathrm{c}$ as a tool for the diagnosis of Type 2 diabetes in 208 premenopausal women with polycystic ovary syndrome. Fertil Steril 2011;96:1275-80.

9. Legro RS. Diabetes prevalence and risk factors in polycystic ovary syndrome. Curr Opin Endocrinol Diabetes 2002;9:451-8.

10. Nehra J, Kaushal J, Singhal SR, Ghaulaut VS. Comparison of Myoinositol versus Metformin on anthropometric parameters in polycystic ovarian syndrome in women. Int J Pharm Pharm Sci 2017;9:144-8.

11. Lerchbaum E, Schwetz V, Giuliani A, Obermayer-Pietsch B. Hypertriglyceridemic waist is associated with impaired glucose tolerance in polycystic ovary syndrome. Nutr Metab Cardiovasc Dis 2013;23:e15-6.

12. Haghighatpanah M, Thunga G, Khare S, Mallayasamy S. Correlation of glycosylated hemoglobin levels with fasting and postprandial glucose in South Indian Type 2 Diabetic patients. Int J Pharm Pharm Sci 2016;8:285-8.

13. Wild RA, Carmina E, Diamanti-Kandarakis E, Dokras A, EscobarMorreale HF, Futterweit W, et al. Assessment of cardiovascular risk and prevention of cardiovascular disease in women with the polycystic ovary syndrome: A consensus statement by the androgen excess and polycystic ovary syndrome (AE-PCOS) society. J Clin Endocrinol Metab 2010;95:2038-49.

14. Hurd WW, Abdel-Rahman MY, Ismail SA, Abdellah MA, Schmotzer CL, Sood A. Comparison of diabetes mellitus and insulin resistance screening methods for women with polycystic ovary syndrome. Fertil Steril 2011;96:1043-7.

15. Peters AL, Davidson MB, Schriger DL, Hasselblad V. A clinical approach for the diagnosis of diabetes mellitus: An analysis using glycosylated haemoglobin levels. Meta-analysis Research Group on the Diagnosis of Diabetes Using Glycated Haemoglobin Levels. JAMA 1996;276:1246-52

16. Tomlinson J, Millward A, Stenhouse E, Pinkney J. Type 2 diabetes and cardiovascular disease in polycystic ovary syndrome: What are the risks and can they be reduced? Diabetes Med 2010;27:498-515.

17. Legro RS, Kunselman AR, Dodson WC, Dunaif A. Prevalence and predictors of risk for type 2 diabetes mellitus and impaired glucose tolerance in polycystic ovary syndrome: A prospective, controlled study in 254 affected women. J Clin Endocrinol Metab 1999;84:165-9.

18. Norman RJ, Masters L, Milner CR, Wang JX, Davies MJ. Relative risk of conversion from normoglycaemia to impaired glucose tolerance or non-insulin dependent diabetes mellitus in polycystic ovarian syndrome. Hum Reprod 2001;16:1995-8. 